RESEARCH REPORT

\title{
Organisational downsizing as a predictor of disability pension: the 10-town prospective cohort study
}

\author{
Jussi Vahtera, Mika Kivimäki, Pauli Forma, Juhani Wikström, Tuomo Halmeenmäki, Anne Linna, \\ Jaana Pentti
}

J Epidemiol Community Health 2005;59:238-242. doi: 10.1136/jech.2004.021824

See end of article for authors' affiliations

....................

Correspondence to: Dr J Vahtera, Finnish Institute of Occupational Health, Hämeenkatu 10, FIN-20500 Turku, Finland; jussi.vahtera@

occuphealth.fi

Accepted for publication 10 June 2004

\begin{abstract}
Objective: To examine whether downsizing, the reduction of personnel in organisations, is a predictor of increased risk of disability retirement among employees who kept their jobs.

Design: Prospective cohort study. Based on reductions of personnel in participants' occupation and workplace, employees were grouped into exposure categories of no downsizing (less than $8 \%$ reduction), minor downsizing (reduction between $8 \%$ and 18\%), and major downsizing (more than 18\% reduction). They were followed up for a five year period after downsizing. Setting: Four towns in Finland.

Participants: 19273 municipal employees, aged 21-54 years.

Main outcome measures: All permanent full disability pensions granted because of medical reasons below 55 years of age between 1 January 1994 and 31 December 1998 from the national registers.

Results: In all, 223 employees were granted a permanent disability pension. The overall rate for disability pensions per 1000 employees was 7.7 after no downsizing, 13.1 after minor downsizing, and 14.9 after major downsizing. Cox proportional hazard models adjusted for age, sex, occupational status, type of employment contract, and town showed 1.81 (95\% confidence intervals 1.22 to 2.70 ) times higher risk of disability retirement after major downsizing than after no downsizing.

Conclusions: The immediate financial advantages of downsizing need to be considered in relation to increased occupational disability and the resulting extra costs to employers and society.
\end{abstract}

$\mathrm{P}$ remature occupational disability is a great burden to the person and extremely costly for society. Risk factors for disability pension include prevalent disease, low self perceived health, health risk behaviours, ${ }^{1-8}$ demographic factors, such as higher age, female sex, low socioeconomic status, and unemployment, ${ }^{168-11}$ and factors related to society and the welfare system. ${ }^{12-14}$ In addition, stressful characteristics of work have been found to be associated with a risk of disability pension. Such characteristics include long working hours, high workload, and low job control. ${ }^{16-8} 15$

In the global economy, expectations of continuing growth have rapidly vanished during the past few years. At the same time, downsizing seems to be an increasingly significant survival tactic for organisations in industrialised countries. ${ }^{16}$ However, such a managerial strategy may pose severe health risks among people who remain employees. Downsizing has been found to be associated with an increased risk of death from cardiovascular disease ${ }^{17}$ as well as heightened morbidity, as indicated by long term sickness absence, ${ }^{18}{ }^{19}$ musculoskeletal symptoms, ${ }^{20}$ poor self rated health, ${ }^{21}$ and health complaints. ${ }^{22}$ Furthermore, downsizing has predicted stressful changes at work, such as reduced job control and increased work demands and job insecurity. ${ }^{19} 20$ Both morbidity and work stress are risk factors for disability retirement. ${ }^{1-8}{ }^{15}{ }^{23}$ However, previous studies directly examining the effect of downsizing on subsequent disability retirement are lacking.

We examined downsizing as a risk factor for permanent disability pensioning among municipal employees who kept their jobs. This downsizing was carried out between 1991 and 1993, during a period of severe economic recession in Finland. Unemployment rose from $3.2 \%$ in 1990 to $16.6 \%$ in 1993, the worst year of the recession. ${ }^{24}$ In 1995 the economy began recovering, but unemployment remained high (14.6\% in 1996). The number of Finnish local government personnel fell by $2.7 \%$ from 1991 to 1992 , by $7.8 \%$ from 1992 to 1993, and by $2.7 \%$ from 1993 to 1994 . As the granting of a disability pension may not solely be determined by illness among older age groups, ${ }^{13} 1425$ our study focused on employees younger than 55 years, the age before which medical causes exclusively determine the granting of disability pensions for municipal employees in Finland.

\section{METHODS}

\section{Participants}

From the 10 towns participating in the Finnish 10-town study, we selected the four (Espoo, Turku, Vantaa, Raisio) in which the employers' computer stored records were available from the beginning of 1991. The total work hours in these towns decreased by $11.3 \%$ from 1991 to 1993 , but only by $1.3 \%$ from 1993 to 1994. Thereafter, the figures turned towards a slight increase. ${ }^{24}$

Of the 23800 full time municipal employees who had been in the service of the towns before downsizing below 53 years of age in 1991, 4527 employees lost or left their jobs during the downsizing in 1992-1993 and were excluded from the study. The participants were all of the 5043 male and 14230 female full time municipal employees who had been in the service of the towns before and during the years of downsizing - that is, over six months both in 1991 and 1993, and were 21 to 54 (mean 40.7) years of age after the downsizing in 1993. Disability retirements were determined from 1994 to 1998. The follow up ceased at the end of 1998 or on the date a disability pension was granted, the person retired for some other reason, died, or reached the age of 55 years.

The approval of the ethics committee of the Finnish Institute of Occupational Health was obtained for the study. 


\section{Assessment of baseline characteristics}

The following baseline characteristics of the participants were derived from the employers' records in 1991-1993: sex; age group (21-39, 40-44, 45-49, 50-54); occupational status (higher grade non-manual, lower grade non-manual, or manual based on the Statistics Finland classification of the five digit occupational titles) ${ }^{26}$; education; type of employment contract (permanent or fixed term); and town. Information on education was collected from a national register kept by Statistics Finland (a database with virtually complete population data on education) and classified as primary to secondary (International Standard Classification of Education (ISCED) levels 1 to 4 ) or tertiary (ISCED 5-6)..$^{27}$

\section{Assessment of organisational downsizing}

The extent of downsizing (reduction in personnel) is an aggregate measure that indicates the decrease in the total number of person years for each occupational group in each town. The reduction in personnel was derived from the employers' records covering all periods of full time employment, including date of commencement and, where appropriate, termination of work contract, and occupational titles as listed by Statistics Finland. ${ }^{26}$ We calculated the percentage reduction in personnel by comparing person years worked in each occupational group for each town in 1993 with the corresponding person years in 1991 (272 categories of degree of downsizing).$^{17}$ Earlier studies have found an increased risk of health problems after downsizing by more than $18 \% .{ }^{17-21}$ Thus the participants were classified into the following groups according to their exposure: no downsizing (reductions in personnel less than $8 \%)$, minor downsizing $(8 \%-$ $18 \%$ ), and major downsizing (more than 18\%).

\section{Assessment of disability pension}

We used the participants' personal identification numbers (a unique number assigned to each Finnish citizen) to collect disability retirement data from the Finnish Local Government Pensions Institution and the State Treasury. These institutions provide complete retirement data as they grant all pensions of employees in the public sector. The dates and causes of early retirement attributable to disability pension (from medical certificates) were obtained for all the participants granted a permanent full disability pension because of medical reasons between 1 January 1994 and 31 December 1998. The underlying cause of the pensioning was assigned according to the International Classification of Diseases. ${ }^{28}$ In addition to carrying out analyses on all cause disability pensions, we considered disability pensions attributable to psychiatric diseases (ICD9 290-319; ICD10 F00F99) and musculoskeletal diseases (ICD9 710-739; ICD10 M00-M99) separately, as they are the two main groups of illnesses leading to disability pension. ${ }^{429}$ The participants were followed up until the date the disability pension was granted, they retired because of some other reason, they died, or they reached the age of 55 years.

\section{Statistical analysis}

To estimate the relative risk of medical retirement, we used Cox proportional hazard models. There was no evidence against the validity of the proportional hazard assumption between downsizing and disability pensioning ( $p$ for trend in the hazard ratio with time 0.128 ). We calculated the hazard ratios and $95 \%$ confidence intervals for the employees remaining at work after minor and major downsizing, using the group of no downsizing as the reference. The hazard ratios were adjusted for sex and age group, and additionally

Table 1 Demographic characteristics of the 19273 participants after downsizing. Figures are percentages unless otherwise stated

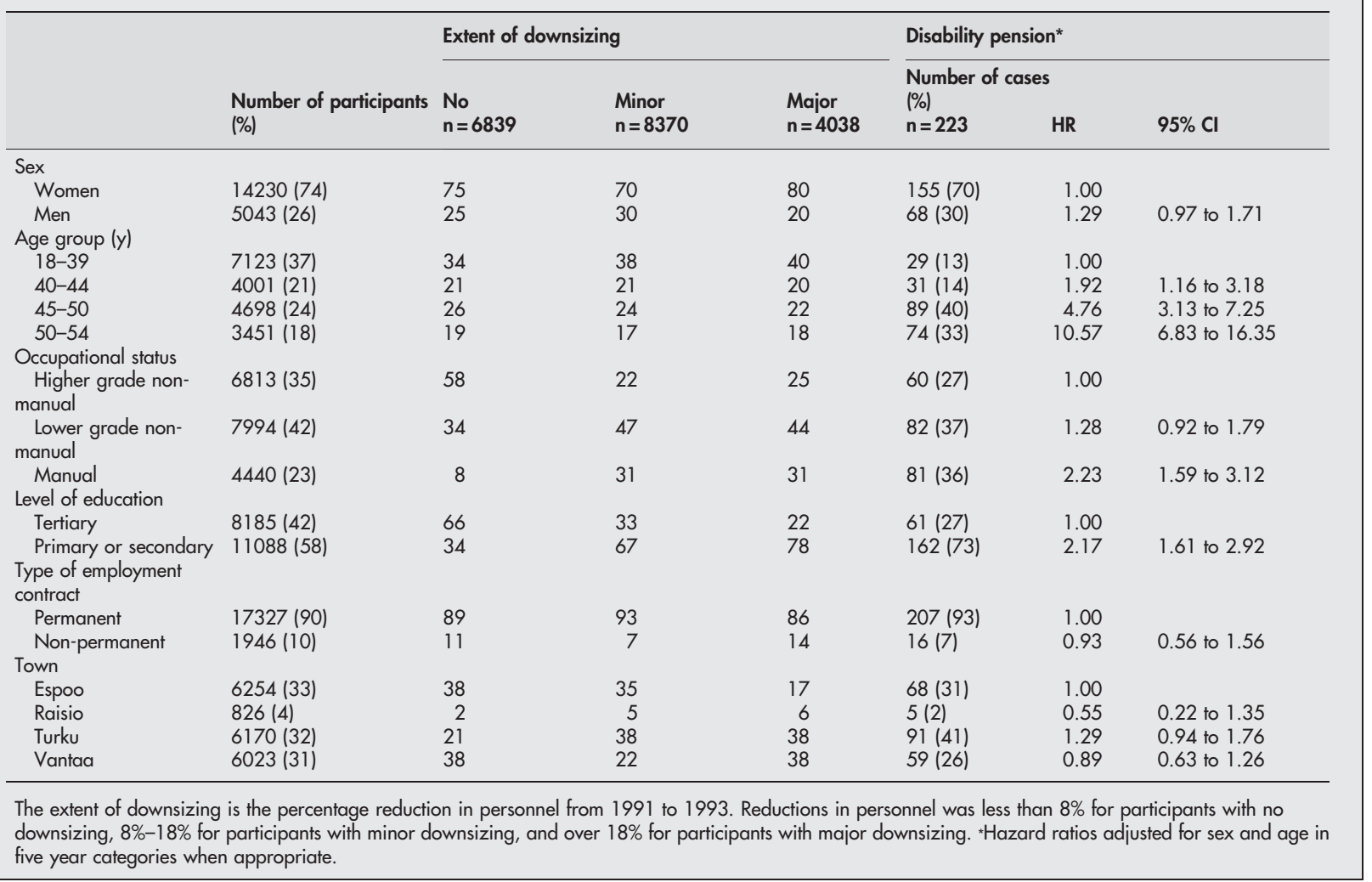


for occupational status, type of employment, and town. The linear trend among the participants was studied treating downsizing as a continuous variable (no downsizing $=0$, minor downsizing $=1$, major downsizing $=2$ ). The differences in the downsizing-disability pension relation between the men and women, and between non-manual and manual employees, were studied by entering the corresponding interaction terms into the models. The analyses were performed using the PHREG procedure in the SAS 8.2 program.

\section{RESULTS}

Table 1 shows the baseline characteristics of the 19273 participants (that is, people who remained in employment) by the extent of downsizing they had experienced. Of them, $74 \%$ were female, $77 \%$ were non-manual employees, and $90 \%$ were permanent employees. The proportions of women, younger employees, and those with lower socioeconomic status and fixed term contract were higher in the major downsizing group $(>18 \%)$ than in other groups. In all, 223 employees were granted a permanent disability pension during the five years after the downsizing. An increased risk of being granted a disability pension was found for older employees and those with lower socioeconomic status.

Table 2 shows the results of the associations between the downsizing and subsequent disability pensioning less than 55 years of age. The overall rate for disability pensions per 1000 employees was 7.7 after no downsizing, 13.1 after minor downsizing and 14.9 after major downsizing. There was a linear trend between downsizing and disability pensioning $(p=0.004)$. After adjustment for age, sex, occupational status, type of employment contract, and town, employees who had experienced major downsizing had a 1.8-fold greater risk of being granted a disability pension when compared with the employees who had not experienced downsizing. Further adjustment for education had little effect on these results (HR after major downsizing 1.6, 95\% CI 1.1 to $2.4 ; \mathrm{p}$ for trend 0.030 ). There was no interaction between sex and downsizing or between occupational status and downsizing with respect to disability pensioning.

The two leading causes of disability were psychiatric diseases (30\% of all disability pensions, 67 cases) and musculoskeletal disorders $(29 \%, 64$ cases). Other causes of disability, including, for example, cancer (24 cases), cardiovascular diseases (14 cases), and injuries (12 cases), were combined. As table 3 shows, downsizing was not associated with disability pensioning attributable to psychiatric diseases. In contrast, the age and sex adjusted hazard ratios for musculoskeletal disorders and other causes were over twofold for those exposed to major downsizing. After further control for occupational status, type of employment, and town these hazard ratios were still over 1.8 .

\section{DISCUSSION}

This is the first study to show that, not only people who lose their jobs, but also those who remain in work after downsizing may be at increased risk of being granted a disability pension. We found an almost twofold risk of disability retirement below 55 years of age among people who remained in employment after major downsizing.

Our study represents a natural experiment on the effects of a changing psychosocial work environment with no accompanying change in material conditions. We used only objective data in the assessment of the constructs under study, eliminating the possibility of reporting bias. The same people were followed up from before any rumour of downsizing, and after it. During the downsizing, only $7.5 \%$ of the participants changed their occupation. Less than $1 \%$ of them moved from non-manual to manual occupations and thus were exposed to increased socioeconomic disadvantage. Because occupational status, education, type of employment contract, and town were controlled, confounding of socioeconomic status or area characteristics is unlikely to explain our results.

It may be argued that early retirement is not determined by illness only. Despite improvements in health and longevity, an increased number of workers retire at a young age. Early retirement provisions of social security systems in developed countries determine the modal age of retirement. ${ }^{14}$ For example, in the United States, only $44 \%$ of men and $24 \%$ of women are still working full time by age $62,{ }^{25}$ and early retirement has been found to be a helpful strategy in effective downsizing endeavours. ${ }^{30}$ However, for several reasons, retirement not related to health is an unlikely explanation for our findings. Firstly, instead of studying early retirement in general, we focused on permanent disability pensions, granted for medical conditions only. Secondly, the extent to which non-medical factors may play a part in disability pensioning is likely to depend on age, being greatest among older age groups. Our finding of a significantly increased disability pension rate after major downsizing among comparatively young employees speaks against the nonmedical retirement argument. Furthermore, downsizing has predicted increased morbidity and cardiovascular mortality among those who remained at work. ${ }^{17-22} 31$ Thirdly, if disability pensioning is a measure of severe health problems, it should show a strong association with mortality. In our data this was the case. After adjustment for age, sex, occupational status, type of employment contract, and town, the mortality rate was 18 -fold (95\% confidence interval 12 to 27) for those retiring before age 55 compared with employees who did not retire during the follow up (data not shown).

Several mechanisms may explain the link between downsizing and permanent disability. One possibility is that employees working with limited capacity because of a

Table 2 Organisational downsizing and relative risk of disability pension from all causes

\begin{tabular}{|c|c|c|c|c|c|c|}
\hline \multirow{3}{*}{$\begin{array}{l}\text { Extent of } \\
\text { downsizing }\end{array}$} & \multirow{3}{*}{$\begin{array}{l}\text { Number of } \\
\text { participants (\%) }\end{array}$} & \multirow{3}{*}{$\begin{array}{l}\text { Number of } \\
\text { cases (\%) }\end{array}$} & \multicolumn{4}{|c|}{ Hazard ratios ( $95 \%$ confidence intervals) } \\
\hline & & & \multicolumn{2}{|c|}{ Age and sex adjusted } & \multicolumn{2}{|c|}{ Fully adjusted* } \\
\hline & & & HR & $95 \% \mathrm{Cl}$ & HR & $95 \% \mathrm{Cl}$ \\
\hline No & $6839(36)$ & $53(24)$ & 1.00 & & 1.00 & \\
\hline Minor & $8370(43)$ & $110(49)$ & 1.76 & 1.27 to 2.44 & 1.46 & 1.02 to 2.08 \\
\hline Major & $4038(21)$ & $60(27)$ & 2.13 & 1.47 to 3.08 & 1.81 & 1.22 to 2.70 \\
\hline$p$ for trend & & & $<0.001$ & & 0.004 & \\
\hline Interaction with sex & & & 0.345 & & 0.212 & \\
\hline $\begin{array}{l}\text { Interaction with } \\
\text { occupational status }\end{array}$ & & & 0.114 & & 0.074 & \\
\hline
\end{tabular}

Reductions in personnel were less than $8 \%$ for participants with no downsizing, $8 \%-18 \%$ for participants with mino downsizing, and over $18 \%$ for participants with major downsizing. *Adjusted for age in five year categories, sex, occupational status, type of employment contract, and town. 
Table 3 Organisational downsizing and relative risk of disability pension attributable to psychiatric and musculoskeletal diseases and other causes. Hazard ratios and their $95 \%$ confidence intervals (in parentheses)

\begin{tabular}{|c|c|c|c|c|c|c|c|c|c|}
\hline \multirow[b]{2}{*}{ Extent of downsizing } & \multicolumn{3}{|c|}{ Psychiatric diseases } & \multicolumn{3}{|c|}{ Musculoskeletal diseases } & \multicolumn{3}{|c|}{ Other causes } \\
\hline & Numbe & HR & $95 \% \mathrm{Cl}$ & Number & HR & $95 \% \mathrm{Cl}$ & Number & HR & $95 \% \mathrm{Cl}$ \\
\hline \multicolumn{10}{|l|}{ Age and sex adjusted } \\
\hline No & 24 & 1.00 & & 13 & 1.00 & & 56 & 1.00 & \\
\hline Minor & 29 & 1.04 & 0.61 to 1.79 & 32 & 2.09 & 1.10 to 3.99 & 120 & 1.80 & 1.31 to 2.48 \\
\hline Major & 14 & 1.06 & 0.55 to 2.06 & 19 & 2.79 & 1.37 to 5.65 & 60 & 2.10 & 1.46 to 3.02 \\
\hline \multicolumn{10}{|l|}{ Fully adjusted* } \\
\hline No & 24 & 1.00 & & 13 & 1.00 & & 56 & 1.00 & \\
\hline Minor & 29 & 1.26 & 0.70 to 2.26 & 32 & 1.29 & 0.65 to 2.59 & 120 & 1.55 & 1.10 to 2.19 \\
\hline Major & 14 & 1.26 & 0.63 to 2.54 & 19 & 1.81 & 0.94 to 3.90 & 60 & 1.89 & 1.27 to 2.81 \\
\hline
\end{tabular}

Reductions in personnel were less than $8 \%$ for participants with no downsizing, $8 \%-18 \%$ for participants with minor downsizing, and over $18 \%$ for participants with major downsizing. *Adjusted for age in five year categories, sex, occupational status, type of employment contract, and town.

longstanding illness cannot cope with increased workload and decreased job control characterising a post-downsizing work situation. ${ }^{19-21}$ In addition to this, major downsizing may influence disability through triggering serious diseases and being associated with declining prognosis in those with preexisting disease, as suggested by studies on cardiovascular diseases. ${ }^{17}$ In our study, the association between downsizing and disability pension was found for physical diseases but not psychiatric disorders. Adverse effects of downsizing on mental health may be particularly strong for those who are made redundant. ${ }^{32}$ Instead, the extent of downsizing may be a less significant predictor of permanent mental health problems among those who are able to keep their jobs.

The downsizing studied by us stemmed from severe economic decline, which affected more or less almost the whole staff. In this context, keeping a job may have been influenced by selection factors, such as good physical and mental health. ${ }^{33}$ Corresponding to earlier findings on morbidity and mortality in this cohort, ${ }^{17}$ the excluded employees who left or lost their job during the downsizing had 1.8 (95\% CI 1.2 to 2.7 ) greater risk of permanent disability pension below 55 years of age. The remaining employees, the focus of this study, had comparatively good health, were young, and worked predominantly in nonmanual occupations, all determinants of a low risk target population for studying risk of disability retirement. Thus, the associations observed in this study between downsizing and permanent work disability may represent an underestimate rather than an overestimate of the actual effect of downsizing.

We focused on four towns in which the average decrease in total work hours was $11 \%$ from 1991 to 1993 . This is well in line with the overall $11 \%$ decrease in the number of Finnish local government personnel. ${ }^{24}$ In this study, the annual incidence of disability pensions being granted was 2.6 per 1000 workers and psychiatric diseases and musculoskeletal disorders accounted for nearly two thirds of the conditions leading to permanent disability on the grounds of which early

\section{Key points}

- Employees who remain in work after downsizing are at increased risk of being granted a disability pension below 55 years of age.

- Downsizing was associated with increased risk of disability pensioning attributable to physical illness, such as musculoskeletal disorders.

- No association was found between downsizing and psychiatric diseases. retirement was granted, figures comparable to those reported elsewhere. ${ }^{413}$ Finally, our findings agree with those obtained elsewhere for the effect of downsizing on work disability, as indicated by very long term sickness absence. ${ }^{31}$ None the less, with only a limited number of cases with specific diseases, we acknowledge that the findings of this study should be validated in further studies with larger samples. Such replications would also help to determine if differences between societies and sectors of work moderate the effects of downsizing on disability pensioning.

\section{Economic implications}

Permanent disability is a great burden, not only on the person, but also on society. At the end of 2002, there were 253500 people in Finland entitled to a disability pension, $7.4 \%$ of the population between 16 and 64 years of age. ${ }^{34}$ The disability pension payments amounted to 2854 million euros-that is, $8 \%$ of all social expenditure that year. It has been predicted that numbers of people fit for work will become a matter of concern in Western Europe, including Finland. ${ }^{35}$

In this study, the annual incidence of disability pensions attributable to downsizing was 0.6 per 1000 workers. For the total of 260000 full time municipal employees being at work below 55 years of age in 1993 in Finland, ${ }^{24}$ this would imply 750 permanent disability pensions to be granted because of the adverse effects of downsizing during the subsequent five years. As the costs of one such pension is about 168500 euros, the estimated total costs from downsizing in terms of extra early disability retirements would have been 126 million euros for the pension institutions.

In summary, permanent occupational disability is a serious consequence of a disabling process. No evidence so far has

\section{Policy implications}

- The strong association found between downsizing and the incidence of disability retirement among employees at a comparatively young age links the problem of disability pensioning to increasingly common changes in modern work life.

- The immediate financial advantages of downsizing need to be considered in relation to the costs resulting from increased disability retirement not only among those who leave or lose their jobs, but also among those who remain at work.

- Downsizing may cause a considerable burden in terms of increased disability pensions and lost years of work life to society. 
existed on changes in work environments that may contribute to this process. The strong association found between downsizing and incidence of disability retirement among employees at a comparatively young age links the problem of disability pensioning to increasingly common changes in modern work life. The immediate financial advantages of downsizing need to be considered in relation to the costs resulting from increased disability retirement not only among those who leave or lose their jobs, but also among those who remain at work. Our evidence suggests that greater extent of downsizing may cause greater burden to society in terms of increased disability pensions and lost years of work life.

\section{Authors' affiliations}

J Vahtera, A Linna, J Pentti, Finnish Institute of Occupational Health, Turku, Finland

M Kivimäki, Department of Psychology, Finnish Institute of Occupational Health, Helsinki, Finland

M Kivimäki, Department of Psychology, University of Helsinki, Finland P Forma, T Halmeenmäki, The Finnish Local Government Pensions Institution, Helsinki, Finland

J Wikström, State Treasury, Helsinki, Finland

Funding: this study was supported by the Academy of Finland (projects 77560, 104891, and 105195), the Finnish Work Environment Fund (projects 101190 and 103432), the Finnish Local Government Pensions Institution, and the participating towns.

Conflicts of interest: none declared.

\section{REFERENCES}

1 Krause N, Lynch J, Kaplan GA, et al. Predictors of disability retirement Scand J Work Environ Health 1997; 23:403-13.

2 Rothenbacher D, Arndt V, Fraisse E, et al. Early retirement due to permanent disability in relation to smoking in workers of the construction industry. J Occup Environ Med 1998;40:63-8.

3 Upmark M, Moller J, Romelsjo A. Longitudinal, population-based study of self reported alcohol habits, high levels of sickness absence, and disability pensions. J Epidemiol Community Health 1999:53:223-9.

4 Brenner H, Ahern W. Sickness absence and early retirement on health grounds in the construction industry in Ireland. Occup Environ Med 2000;57:615-20.

5 Borg K, Hensing G, Alexanderson K. Predictive factors for disability pension-an 11 -year follow up of young persons on sick leave due to neck, shoulder, or back diagnoses. Scand J Public Health $2001 ; 29: 104-12$.

6 Hagen KB, Tambs K, Bjerkedal T. A prospective cohort study of risk factors for disability retirement because of back pain in the general working population. Spine 2002;27:1790-6.

7 Karpansalo M, Manninen P, Lakka TA, et al. Physical workload and risk of early retirement: prospective population-based study among middle-aged men. J Occup Environ Med 2002;44:930-9.

8 Krokstad S, Johnsen R, Westin S. Social determinants of disability pension: a 10-year follow-up of 62000 people in a Norwegian county population. Int J Epidemiol 2002;31:1183-91.

9 Westin S, Schlesselman JJ, Korper M. Long-term effects of a factory closure: unemployment and disability during ten years' follow-up. J Clin Epidemiol 1989:42:435-41.
10 Mansson NO, Rastam L, Eriksson KF, et al. Socioeconomic inequalities and disability pension in middle-aged men. Int J Epidemiol 1998;27:1019-25.

11 Guberan E, Usel M. Permanent work incapacity, mortality and survival without work incapacity among occupations and social classes: a cohort study of ageing men in Geneva. Int J Epidemiol 1998;27:1026-32.

12 Jacobs K, Kohli M, Rein M. Testing the industry-mix hypothesis of early exit. In: Kohli M, Rein M, Guillemard AM, et al. Time for retirement. New York: Cambridge University Press, 1991.

13 Poole CJM. Retirement on grounds of ill health: cross sectional survey in six organisations in united kingdom. BMJ 1997:314:929.

14 Gruber J, Wise D. Social Security, retirement incentives, and retirement behavior: an international perspective. EBRI Issue Brief 1999;209:1-22.

15 Lund T, Iversen L, Poulsen KB. Work environment factors, health, lifestyle and marital status as predictors of job change and early retirement in physically heavy occupations. Am J Ind Med 2001;40:161-9.

16 Hurrell JJ. Editorial. Am J Public Health 1998;88:1012-13.

17 Vahtera J, Kivimäki M, Pentti J, et al. Organisational downsizing, sickness absence and mortality: the 10-town prospective cohort study. BMJ 2004;328:555-7.

18 Vahtera J, Kivimäki $M$, Pentti J. Effect of organisational downsizing on health of employees. Lancet 1997;350:1124-8.

19 Kivimäki M, Vahtera J, Pentti J, et al. Factors underlying the effect of organisational downsizing on health of employees: longitudinal cohort study. BMJ 2000:320:971-5.

20 Kivimäki M, Vahtera J, Ferrie J, et al. Organizational downsizing and musculoskeletal problems in employees: a prospective study. Occup Environ Med 2001;58:811-17.

21 Kivimäki M, Vahtera J, Pentti J, et al. Downsizing, changes in work, and selfrated health of employees: a 7-year 3-wave panel study. Anxiety, Stress and Coping 2001;14:59-73.

22 Quinlan M, Mayhew C, Bohle P. The global expansion of precarious employment, work disorganization, and consequences for occupationa health: a review of recent research. Int J Health Serv 2001;31:335-414.

23 Kivimäki M, Forma $P$, Wikström J, et al. Sickness absence as a risk marker of future disability pension: the 10-town study. J Epidemiol Community Health 2003;58:710-11

24 Statistics Finland. Statistical yearbook of Finland. Helsinki: Statistics Finland, 2000.

25 Woodbury RG. Early retirement in the United States. Stat Bull Metrop Insur Co 1999;80:2-7

26 Statistics Finland. Classification of occupations, handbook no 14. Helsinki: Statistics Finland, 1987.

27 Statistics Finland. Unesco's international standard classification of education. Finnish implementation manual. Helsinki: Statistics Finland, 1999.

28 World Health Organisation. International classification of diseases, injuries and causes of death, ninth and tenth revisions. Geneva: WHO, 1977 and 1992.

29 Rodgers LM. A five year study comparing early retirements on medical grounds in ambulance personnel with those in other groups of health service staff. Part II: causes of retirements. Occup Med 1998;48:119-32.

30 Young S, Brown HN. Effects of hospital downsizing on surviving staff. Nurs Econ 1998;16:258-62.

31 Westerlund H, Ferrie J, Hagberg J, et al. Workplace expansion, long-term sickness absence, and hospital admission. Lancet 2004;363:1193-7.

32 Keefe V, Reid P, Ormsby C, et al. Serious health events following involuntary job loss in New Zealand meat processing workers. Int J Epidemiol 2002;31:1155-61.

33 Ferrie JE. Labour market status, insecurity and health. J Health Psychol 1997;2:373-97.

34 Finnish Centre for Pensions, Social Insurance Institution. Statistical yearbook of pensioners in Finland. Helsinki: Finnish Centre for Pensions, 2003.

35 Ministry of Social Affairs and Health. Report by the SOMERA Committee. Committee on the Development and Financing of Social Expenditure. Committee Report 2002:4. Helsinki: Ministry of Social Affairs and Health 2002. 